\title{
E Cape's corruption-busting DG finally ousted
}

Dr Siva Pillay, the IT-savvy, corruptionbusting Nelson Mandela Bay doctor and millionaire businessman, has been edged out as Superintendent-General of the controversy-riddled Eastern Cape Health Department, after a long-standing feud with his Health MEC, Sicelo Gqobana.

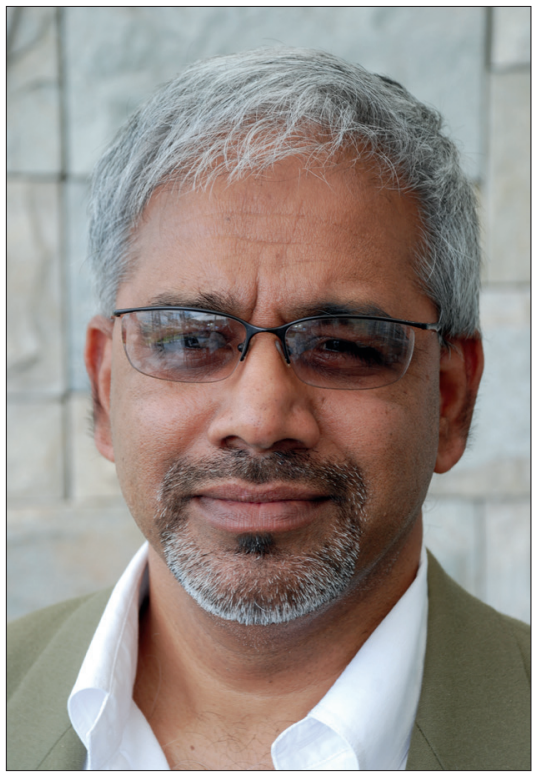

Dr Siva Pillay has been ousted as Superintendent General of the Eastern Cape Health Department.

His (acting) replacement is Mahlubandile Qwase, a teacher, former MEC for Education, former chair of the provincial health portfolio committee and former deputy director-general in Premier Noxolo Kieviet's office. Counting MEC Gqobana, this puts two teachers at the helm of the provincial health department.

Pillay's posting was directly influenced by national health minister Dr Aaron Motsoaledi. Since his 2009 appointment he has sacked 1284 departmental staff, for offences ranging from corruption to nonperformance and incapacity - outstripping any operational health chief in the country. He boasts that he saved R1.4 billion in duplicate and/or corrupt payments; used identity numbers and plumbed the department's IT procurement and salary system to construct star-burst charts of top officials using multiple service provider companies run by relatives or friends; fired the entire regional leadership of the ambulance service for flying private patients, at a cost to taxpayers of R25 million; and exposed an internal scam involving gas cylinder supplies to hospitals, reaching an out-of-court settlement of some R40 million. His is the only department in the Eastern Cape to have implemented approved reversals of approximately 1000 irregular promotions, amounting to R80 million per annum in the health department alone, a saving of some R400 million over 5 years. Among several other scams, he and a dedicated fraud-busting team also uncovered a multi-million rand state drugdepot wholesaling network.

\section{Withdrawn resignation suddenly revived}

Pillay's contract as operational health chief was due to expire on 31 January this year. However, it was suddenly terminated halfway through December 2012, citing a resignation he submitted in June 2012 and which Eastern Cape Premier Noxolo Kieviet persuaded him to withdraw after national intervention. ${ }^{[1]}$

\section{I've re-applied for the job only because I believe I can add value. If I really wanted to resign why would I re-apply?' he asked, adding that he stayed on until 22 December last year, 'hoping to help - but no one gave me the time of day.'}

This abortive resignation followed a chaotic period during which 4000 Eastern Cape healthcare workers, including 67 doctors, went unpaid for nearly 5 months, with Pillay taking the heat after an internal political campaign robbed him of the human resources and several other core operational functions. Only the intervention of ANC Secretary-General Gwede Mantashe and Aaron Motsoaledi, on the eve of his 2-week resignation deadline, prevented Pillay leaving. 
Well before that, from November 2011, Pillay had lost control of the air and land ambulance rescue services to the transport department, while the human resources operational functions were moved to the provincial treasury. The Premier's office set up a provincial Health Infrastructure Management Committee, usurping his infrastructure leadership. He ran the department without deputy director generals for clinical services and human resources or a chief financial officer, and later his supply chain management function was taken away. Meanwhile, his budget allocation showed negative growth.

\section{His is the only department in the Eastern Cape to have implemented approved reversals of approximately 1000 irregular promotions, amounting to (just in health) R80 million per annum, $a$ saving of some R400 million over five years.}

\section{'Nail E-Cape corruption or NHI fails' - Section 27}

This was described at the time by Mark Heywood, director of Section 27 (an NGO which includes the Treatment Action Campaign), as 'legally impermissible, let alone morally outrageous in a health context'. Heywood said the Eastern Cape could 'wave goodbye' to a National Health Insurance (NHI) system should the failure to address systems as critical as human resources, supply chain management and endemic corruption continue.

Pillay commented at the time, 'It's a recipe for failure to tell me to fix it.' An internal task team consisting of the Premier, Pillay's department, MEC Gqobana and Provincial Treasury was hastily set up mid-year to co-ordinate and monitor all planning. The premier agreed to 'reign in' the feuding Pillay and Gqobana should they deviate from agreed-upon goals and strategies. This 'paper-agreement' lasted until Pillay's edging-out in mid-December.

So unprecedented were Pillay's corruption-busting initiatives that Pretoria chose to pilot a hi-tech multiagency national programme for proper procurement and monitoring from his office. Consisting of the Hawks, the Asset Forfeiture Unit, National Treasury, the SA Revenue Service and the Special Investigations Unit, the multi-agency task team (known as MAWG), bragged that it would cut fraud and wastage by up to $80 \%$. However, many of its members were discouraged by the on-going political in-fighting, which they felt white-anted its state-of-the-art anti-corruption and service delivery initiatives. According to Izindaba sources, the current controversy is being discussed at the highest levels of the ANC and Motsoaledi is demanding answers as to why the dispute resolution mechanism appears to have failed so spectacularly.

Some of Pillay's biggest clashes with the 'union-friendly' Gqobana centred on tender procedures, as well as Pillay's attempts to rationalise a hugely unwieldy and inefficient service delivery platform in order to match scarce human resources and achieve cost efficiencies. Insiders at Bhisho spoke of Pillay once marching into Gqobana's boardroom where a prospective IT supplier was making a presentation for a province-wide 'virtual provider network' (VPN) tender, linking a wide sprawl of healthcare facilities. 'Pillay demanded to know what was going on because the tender closing date had already expired', resulting in a major face-down with his political chief in front of an embarrassed presenter, the source said.

Another, more recent clash centred on Gqobana's reinstatement of some staff whom Pillay had sacked for not being registered with the Health Professions Council of South Africa (HPCSA). Pillay apparently uncovered more than 600 employees who were not registered with the Pharmacy Council, Nursing Council or Medical and Dental Professions Board, which enabled immediate dismissal.

'I'll continue doing all I can' - Pillay Pillay has since applied for a district specialist post (and re-applied alongside other contenders for his old job). He told Izindaba, 'I left parliament as an MP in December 2009 because I thought I could make a difference. In spite of all I encountered I stuck it out because I really believed I was making that difference. As a health activist you do not want to abandon ship, but certain circumstances forced me to resign in June when I hit the wall. When that resignation was not accepted, I devoted myself to changing the service, turning up and fighting strong, but my contract was not renewed. I've re-applied for the job only because I believe I can add value. If I really wanted to resign, why would I re-apply?' He added that he stayed on until 22 December last year, 'hoping to help - but no one gave me the time of day'.
At the height of his tenure, Pillay survived a night-time murder attempt by a pistolwielding motorcyclist near the entrance to Mdantsane township, which left bullet holes in his vehicle, ${ }^{[2]}$ as well as a dusk confrontation with a side-arm-carrying man in the deserted health department car park after work in Bhisho, during which the exit was blocked by a BMW. ${ }^{[3]}$ Prior to these incidents, he and his wife were threatened face-to-face and telephonically by relatives of sacked senior officials, one telling Pillay: 'Don't forget this is Bhisho; some of what you sow, you shall reap. The pit we're digging for you is getting deeper and deeper and when we bury you, no-one will ever get you out. ${ }^{[3]}$

The SAMJ has e-mailed repeated, detailed questions to top Eastern Cape government officials (and referred to the Health MEC's office), and followed up with telephone calls and SMSes. However, after 3 weeks, no answer has been received. Izindaba suggested that a response by the Health MEC would be inappropriate (except on the allegation of tender interference), given his feud with Pillay, and that Premier Kieviet should respond instead, but this was simply ignored.

His abortive June 2012 resignation followed a chaotic period during which 4000 Eastern Cape healthcare workers, including 67 doctors, went unpaid for nearly 5 months, with Pillay taking the heat after an internal political campaign robbed him of the human resources and several other core operational functions.

An excerpt from Izindaba's e-mail to Bhisho reads: 'Collectively these moves give rise to serious questions as to their motivation, (given for example, [Pillay's] previous firing of the regional air ambulance service chiefs for abusing the service with private patients to the tune of R25 million). Dr Pillay was also intimately involved in the Multi-AgencyWork-Group for proper procurement and monitoring (and corruption busting) and has two publicly documented attempts on his life. The removal of an SG appropriately clinically qualified to understand and run a provincial health department 
(plus his reported achievements) and his replacement with a teacher (albeit acting and a local government veteran) also requires some comment from yourselves. Without a considered response from your office, these facts, when taken together, imply that something is seriously wrong with the state of healthcare government in the Eastern Cape.'
Bhisho's last word on the matter (an e-mail of 24 Februay, 09h57), reproduced verbatim here, was: 'Dear Mr Bateman, this mater [sic] can actually be death (sic) with by the Office of the MEC. It has been forwarded to them for further handling - Manelisi Wolela, GM Provincial Communication System.' Eight working days and an SMS reminder later, there was still no reply.

\section{Chris Bateman}

chrisb@hmpg.co.za

1. Bateman C. Pretoria intervention saves E-Cape corruptionbuster. S Afr Med J 2012:102:591-592.

. B C. Port Elizabeth's tertiary care reaches crisis point. S Afr Med J 2012;102(9):720-722.

3. Bateman C. Corruption busting a real health threat. S Afr Med J 2011;101:360-363.

S Afr Med J 2013;103(4):215-217.

DOI: $10.7196 / 6862$ 